\title{
Generating tsunami risk knowledge at community level as a base for planning and implementation of risk reduction strategies
}

\author{
S. Wegscheider ${ }^{1}$, J. Post ${ }^{1}$, K. Zosseder ${ }^{1}$, M. Mück ${ }^{1}$, G. Strunz ${ }^{1}$, T. Riedlinger ${ }^{1}$, A. Muhari ${ }^{2}$, and H. Z. Anwar ${ }^{3}$ \\ ${ }^{1}$ German Remote Sensing Data Center, German Aerospace Center (DLR), Muenchner Str. 20, 82234 Wessling, Germany \\ ${ }^{2}$ Ministry of Marine Affairs (DKP), Jakarta, Indonesia \\ ${ }^{3}$ Indonesian Institute of Sciences (LIPI), Research Center for Geotechnology, Bandung, Indonesia
}

Received: 13 August 2010 - Revised: 30 October 2010 - Accepted: 5 December 2010 - Published: 1 February 2011

\begin{abstract}
More than 4 million Indonesians live in tsunamiprone areas along the southern and western coasts of Sumatra, Java and Bali. Although a Tsunami Early Warning Center in Jakarta now exists, installed after the devastating 2004 tsunami, it is essential to develop tsunami risk knowledge within the exposed communities as a basis for tsunami disaster management. These communities need to implement risk reduction strategies to mitigate potential consequences.

The major aims of this paper are to present a risk assessment methodology which (1) identifies areas of high tsunami risk in terms of potential loss of life, (2) bridges the gaps between research and practical application, and (3) can be implemented at community level. High risk areas have a great need for action to improve people's response capabilities towards a disaster, thus reducing the risk. The methodology developed here is based on a GIS approach and combines hazard probability, hazard intensity, population density and people's response capability to assess the risk.

Within the framework of the GITEWS (GermanIndonesian Tsunami Early Warning System) project, the methodology was applied to three pilot areas, one of which is southern Bali. Bali's tourism is concentrated for a great part in the communities of Kuta, Legian and Seminyak. Here alone, about 20000 people live in high and very high tsunami risk areas. The development of risk reduction strategies is therefore of significant interest. A risk map produced for the study area in Bali can be used for local planning activities and the development of risk reduction strategies.
\end{abstract}

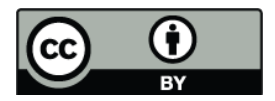

Correspondence to: $\mathrm{S}$. Wegscheider (stephanie.wegscheider@dlr.de)

\section{Introduction}

The devastating tsunami of 26 December 2004 significantly raised public awareness about the hazard of tsunamis and the need for tsunami early warning in the Indian Ocean (Rudloff et al., 2009). This event led to broad international efforts to design and implement a tsunami early warning system for the Indian Ocean on one hand, and on the other, to urgently strengthen community-based disaster management strategies (e.g. awareness raising, preparedness strategies), the socalled "last mile" (Taubenböck et al., 2009). In order to set up an effective disaster management strategy, it is essential to assess and monitor the tsunami hazard, a population's risk and the population's vulnerability on a continuous basis (especially with regard to and in the context, of early warning) (Rynn and Davidson, 1999; UN/ISDR, 2004; Bird and Dominey-Howes, 2008; UNESCO IOC, 2009; Taubenböck et al., 2009).

One key element of community-based disaster management is evacuation planning (Papathoma, 2003; UNESCO IOC, 2009; Post et al., 2009b; Taubenböck et al., 2009; Dall'Osso and Dominey-Howes, 2010; Spahn et al., 2010). This is a vital element of an effective risk reduction strategy. It requires amongst other things the determination of evacuation zones, the identification of evacuation target points, and the specification of evacuation routes to reach those points (Papathoma, 2003; Dall'Osso and Dominey-Howes, 2010). Being aware of the risk and being prepared if the worst comes to the worst, having a clearly defined evacuation strategy is important for decreasing people's vulnerability to tsunamis and thus, their risk (UNESCO IOC, 2009).

The main objectives of this paper are to present a risk assessment methodology which (1) identifies areas of high

Published by Copernicus Publications on behalf of the European Geosciences Union. 


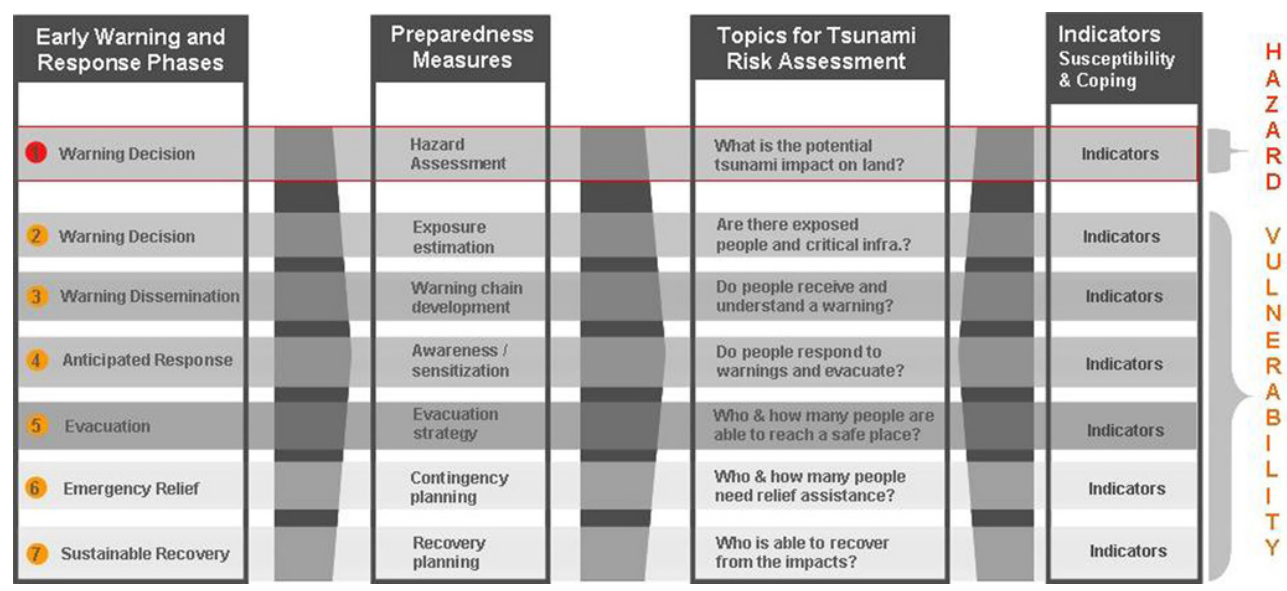

Fig. 1. Conceptual vulnerability framework of GITEWS (Post et al., 2009c).

Table 1. Flux classes and stability of persons and buildings.

\begin{tabular}{lll}
\hline Flux $\left(\mathrm{m}^{2} / \mathrm{s}\right)$ & Effect on persons & Effect on buildings \\
\hline$<1$ & stable & stable \\
$1-7$ & unstable & possibly partial damage \\
$>7$ & unstable & destruction \\
\hline
\end{tabular}

Sources: Jonkman and Vrijling 2008, RESCDAM 2000, CDIT 2009.

tsunami risk in terms of potential loss of life, (2) bridges the gaps between research and practical application, and (3) can be implemented at community level. Where high risk areas are identified, there is an urgent need for action by the local authorities to improve the response capability of the population, thus reducing the risk. The identification of high risk areas raises the awareness of vulnerable "hotspots" and provides information vital to the support of emergency decision making. The official activities of planning and implementing risk reduction measures, like the construction of tsunami shelters, the governance of construction activities, the signposting of evacuation routes, or the installation of structural and natural coastal protection measures (Papathoma, 2003; UNESCO IOC, 2009; Dall'Osso and DomineyHowes, 2010) need to be prioritized. In order to allow local authorities to integrate and implement risk information quickly in their disaster management, the applied method needs to bridge the gap between sophisticated research and practical application.

\section{Methodology}

In order to achieve these objectives, comprehensive hazard, vulnerability and risk assessments have to be performed. A hazard as an event potentially causing loss of life, injury, property damage, social and economic disruption or environ- mental degradation, is characterised by its location, intensity, frequency and probability (UN/ISDR, 2004). Vulnerability is a complex interaction of physical, social, economic, and environmental factors or processes which determine the probability and degree of susceptibility of a community or individual to the impact of a given hazard (UN/ISDR, 2004). As risk is conventionally expressed by the equation

Risk $=$ Hazard $\times$ Vulnerability

risk assessment is a logical outcome of the processes hazard and vulnerability assessments (UNESCO IOC, 2009).

Within the German-Indonesian Tsunami Early Warning System (GITEWS) project, a conceptual framework was developed (Post et al., 2007a, b) and applied in this study (see Fig. 1). This framework comprises the different phases of the disaster cycle from preparedness and early warning to emergency response and recovery. In the following, the components $1-5$ of Fig. 1 are described in more detail, handling both hazard and vulnerability components.

Risks are dynamic (UNESCO IOC, 2009) and in view of the necessity to keep risk information up-to-date and our aim to enable local authorities to integrate risk assessment into their planning processes, the method described here is based on techniques which are available and usable even in developing countries like Indonesia. Therefore, except for the hazard assessment, all analyses are GIS-based methods which can also be applied using open-source software.

\subsection{Hazard assessment}

Hazard assessment is a basic and crucial step for risk assessment. Based on a series of tsunami modeling results, a probabilistic multi-scenario approach was taken. For the studied area of Kuta in Bali, high resolution tsunami modeling with a spatial resolution of up to $10 \mathrm{~m}$ was provided by GKSS/DHIWASY (Gayer et al., 2008). 

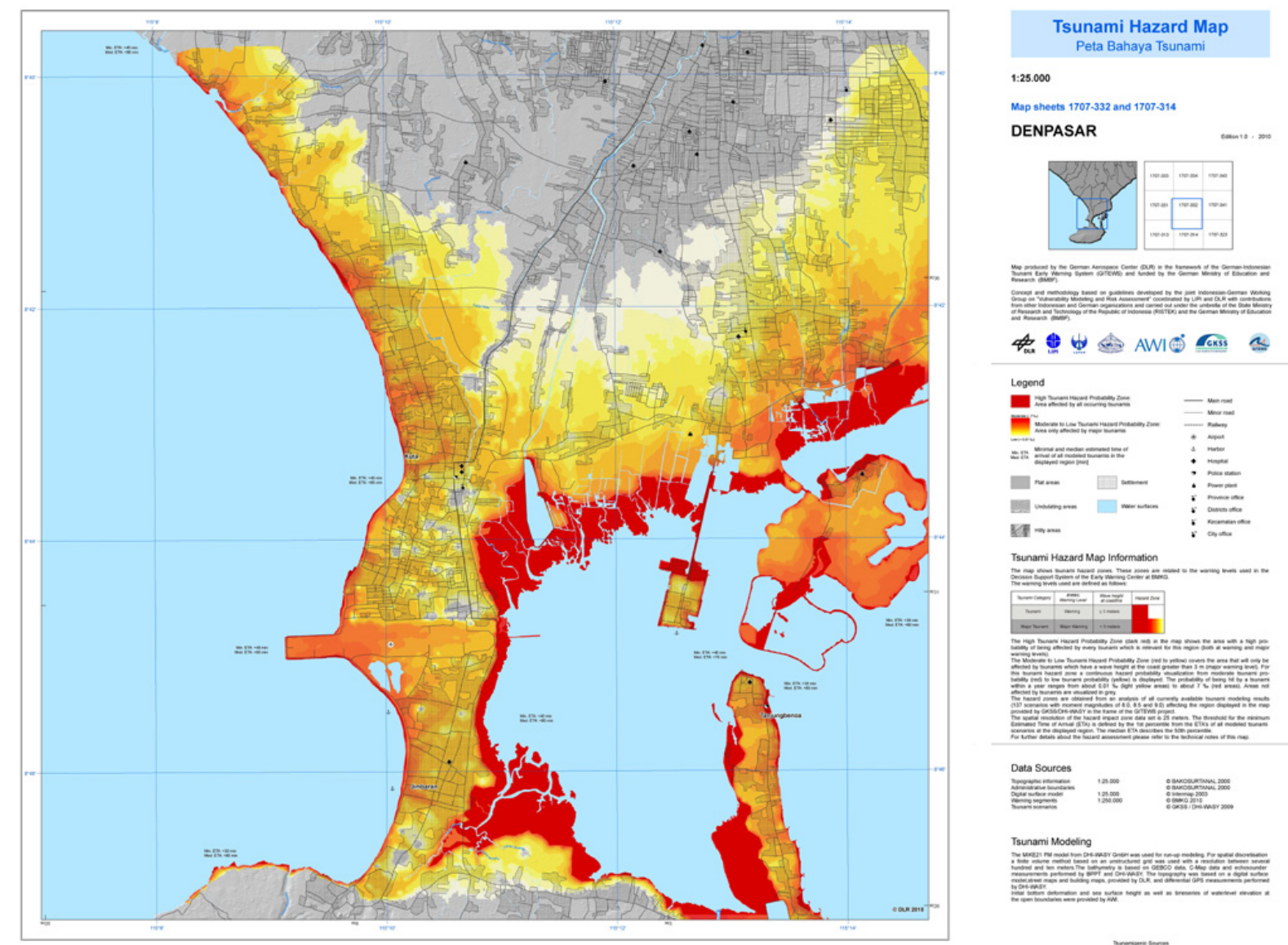

DENPASAR
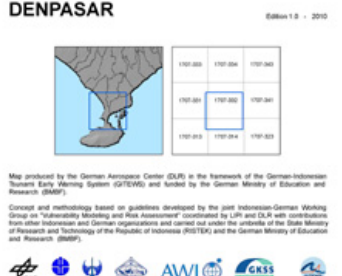

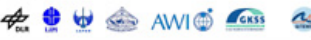
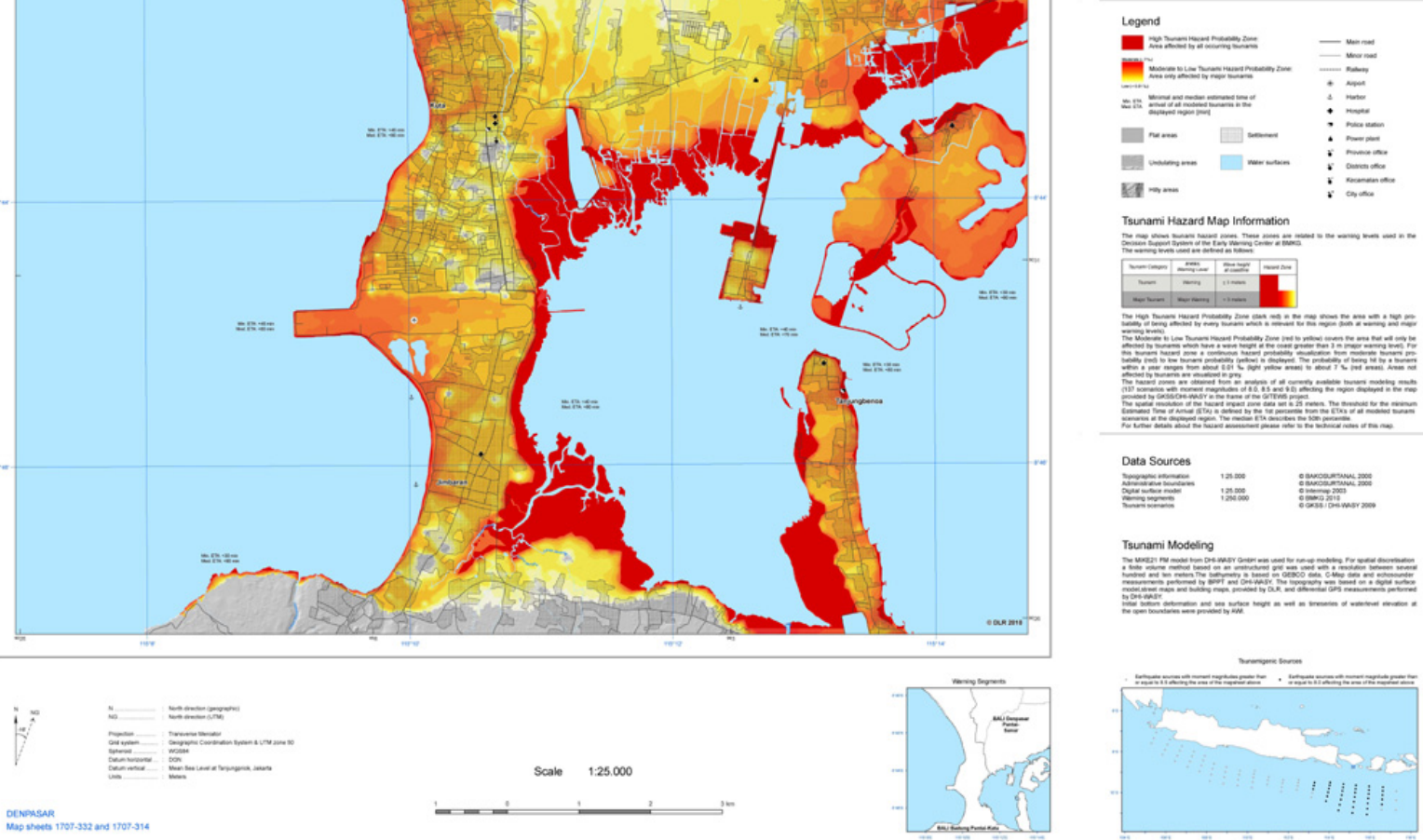

Fig. 2. Tsunami Hazard Map for Bali.

Tsunami modeling considers various source locations in the Sunda Trench where tsunamigenic earthquakes affecting Bali may occur. Tsunami wave propagation and inundation on land are modelled for each location and earthquakes of various magnitudes $\left(M_{\mathrm{w}}=8.0,8.5\right.$ or 9.0$)$ (Babeyko et al., 2010). The likelihood of earthquake occurrence at a specific source location and of a certain magnitude varies along the Sunda Trench (McCloskey et al., 2008; Clieh et al., 2008; Latief et al., 2000). The modeling results available affecting the area of interest (in the case of Bali, 137 scenarios) are then used to assess the likelihood that a point on land will be inundated (see Fig. 2). The combination of the earthquake occurrence probability and the inundation probability leads to an overall probability value that a point on land will be affected by a tsunami within a certain time frame. A detailed description of the assessment process is available in Zoßeder et al. (2009) and Strunz et al. (2011).
In addition to providing predictions of wave heights, the modeling provides information about the estimated time of arrival of the tsunami wave at the coast and the parameter of flux, which is a function of flow velocity and inundation depth. Various studies investigated depth-velocity combinations resulting in instability for persons or buildings (e.g. Jonkman and Vrijling, 2008; RESCDAM, 2000). The flux values of all scenarios were therefore statistically analysed and spatially classified into three classes representing zones of potential stability and instability of persons and buildings (see Table 1).

\subsection{Vulnerability assessment}

Vulnerability is a complex system of various components. Some key components are shown in Fig. 1. The quantification of these components is an important task on the way to determining the risk (Post et al., 2007a). Two main elements 
Table 2. Classification of risk assessment input data.

\begin{tabular}{lll}
\hline Parameter & Value range & Class \\
\hline \multirow{3}{*}{ Hazard probability } & $\begin{array}{l}0-1 \% \text { of probability range } \\
1-10 \% \text { of probability range } \\
10-100 \% \text { of probability range }\end{array}$ & $\begin{array}{l}\text { Low probability } \\
\text { Medium probability } \\
\text { High probability }\end{array}$ \\
\hline \multirow{2}{*}{ Hazard intensity } & $<1 \mathrm{~m}^{2} / \mathrm{s}$ & Low intensity \\
& $1-7 \mathrm{~m}^{2} / \mathrm{s}$ & Medium intensity \\
& $>7 \mathrm{~m}^{2} / \mathrm{s}$ & High intensity \\
\hline \multirow{3}{*}{ Population density } & $<100$ persons $/ \mathrm{km}^{2}$ & Low density \\
& $100-2500$ persons $/ \mathrm{km}^{2}$ & Medium density \\
& $>2500$ persons $/ \mathrm{km}^{2}$ & High density \\
\hline \multirow{2}{*}{ Response capability } & $\mathrm{ET}^{1}>\mathrm{AT}^{2}$ & Weak response capability \\
& $\mathrm{ET}^{1} \leq \mathrm{AT}^{2}$ & Good response capability \\
\hline
\end{tabular}

${ }^{1}$ Evacuation time; ${ }^{2}$ Time available for evacuation

of vulnerability are exposure of the population and people's response capability.

Available population distribution information is mainly based on census data at community level. For the purpose of tsunami vulnerability assessment, such data sets are not detailed enough. It is necessary to know precisely the spatial distribution of people within a community at risk to tsunami hazard. People being exposed to a tsunami hazard (i.e. residing in a potential tsunami inundation zone) are not uniformly vulnerable to tsunami damage (Bird and Dominey-Howes, 2008), as their vulnerability is defined by a complex combination of aspects (see Fig. 1). Our approach is based on a probabilistic hazard assessment, and as the tsunami hazard probability typically decreases with increasing distance to the coast (see Fig. 2), people near the coast have a higher probability of being exposed than those farther away. Thus, it is a great difference, if, within one administrative unit, a settlement is located close to the coastline or inland.

Khomarudin et al. $(2009,2010)$ developed a method to model the population distribution based on census, statistical and land use data. Statistical data such as the main source of income are used to gain information about peoples whereabouts throughout the day, and weighting factors are derived. These weightings are then used to disaggregate census population data to spatially more explicit land use units resulting in detailed population distribution maps.

People's response capability highly depends on time. A good response capability means that the population is able to reach a safe place in time before a tsunami strikes. Different time components play a role and have to be quantified to assess response capability. Tsunami modeling provides information about the wave's travelling time from its source location to the coast. The multi-scenario approach used here provides results with different estimated times of arrival (ETA) of the tsunami wave for each single scenario. For a conser-

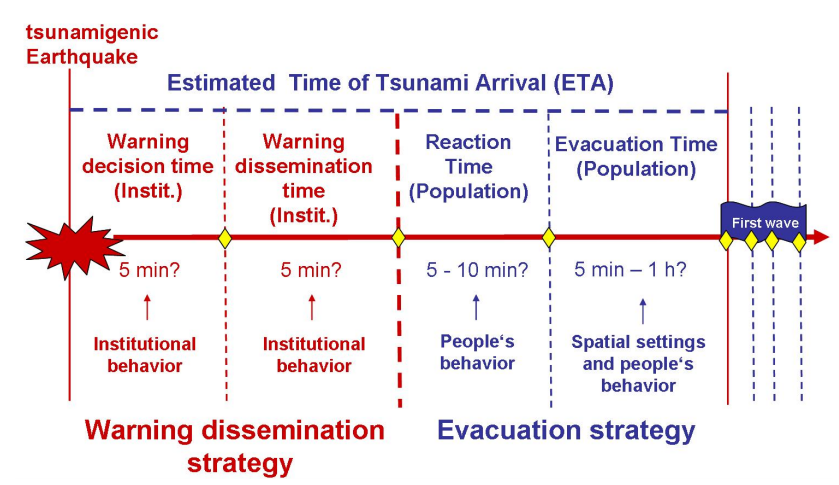

Fig. 3. Relevant time components for the assessment of human response capability to tsunami warning (Post et al., 2009a).

vative or worst-case approach in assessing the response capability, the minimum ETA of all scenarios is taken but using the 1st percentile from all modeled ETAs as the threshold.

In general, the whole time frame set by the ETA cannot be used for actual evacuation measures. The time frame is usually decreased by various components shown in Fig. 3. These time components can be divided into two groups: those depending (1) on institutional behaviour and (2) on people's behaviour.

Following Post et al. (2009b), the time spans related to (1), i.e. warning decision time (time consumed by detection of a potentially tsunamigenic earthquake until the decision to disseminate a warning) and warning dissemination time (time consumed by technical transmission of the warning from the warning center to local devices and institutions and further transmission from there to the people at risk), are presumed as five and three minutes respectively. Consequently, there is a reduction in the time potentially available for evacuation of eight minutes. This assumption disregards the possibility 


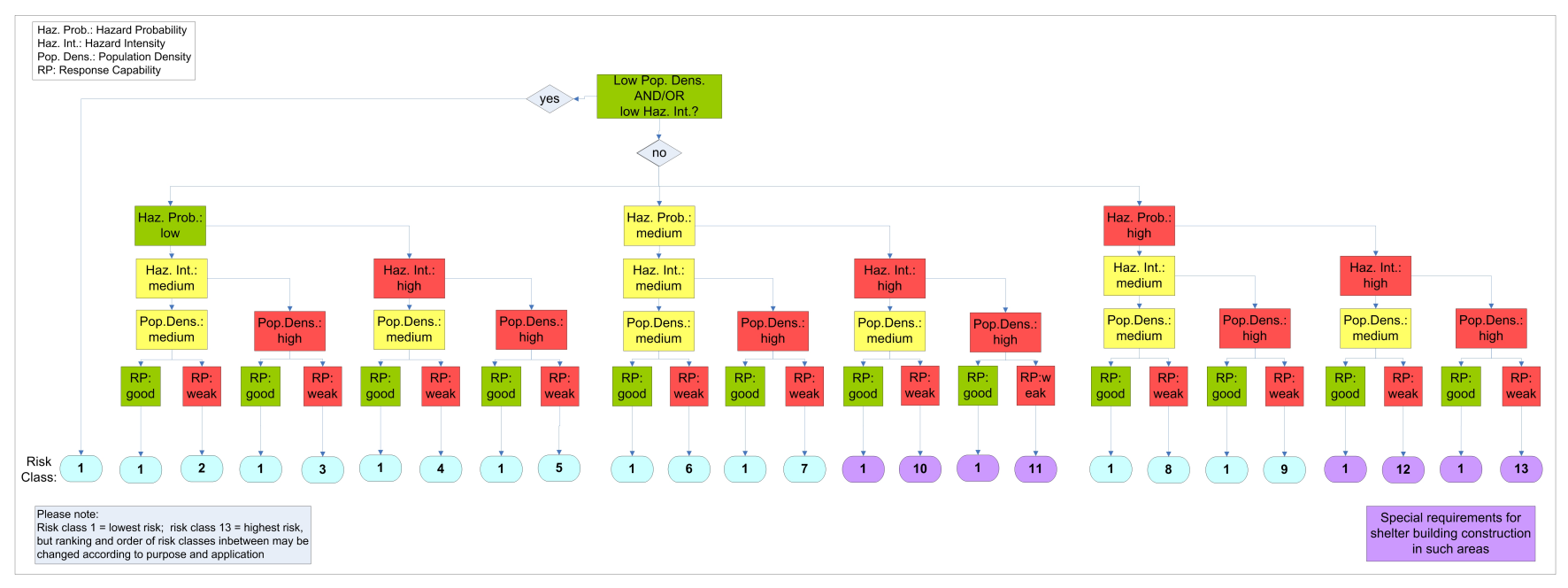

Fig. 4. Decision tree for determination of risk classes.

that people might start evacuating even before they receive an institutional (technical) warning, based on natural warning signs such as earthquakes.

The time components related to (2), reaction time and evacuation time, are difficult to assess. Post et al. (2009b) concluded that a quantification of the reaction time, i.e. the time that passes between receiving a warning by people at risk, to their decision to start evacuating, is currently not possible due to insufficient availability of required data. Thus, an almost ideal reaction time of two minutes, i.e. an almost immediate reaction after receiving a warning, is presumed. The limitations arising from this presumption and their resulting consequences will be discussed later.

The assessment of evacuation time, i.e. the time needed to reach a safe place, depends on various parameters: (i) extent of hazard impact area (i.e. potential inundation area), (ii) location and characteristics of tsunami safe areas, (iii) characteristics of evacuation paths (land cover, slope, etc.), (iv) population density, (v) age and gender distribution within the population, and (vi) location of critical facilities (i.e. facilities with people of reduced or lacking physical abilities to evacuate such as hospitals or schools) (Post et al., 2009b; UNESCO IOC, 2009).

The basic principle to assess the time needed for evacuation is a GIS analysis based on a cost-weighted distance approach to define the fastest path (i.e. the best evacuation route) from any given point to a safe area. Details of this approach are available in Post et al. (2009a, b).

Based on the modeled evacuation time (ET) and the maximum time available for evacuation (AT), it is possible to identify safe areas to evacuate to before the tsunami arrives. Target locations for evacuees can either be shelter areas (horizontal evacuation) or shelter buildings (vertical evacuation). Buildings which potentially can serve as shelter were identified in a building survey conducted by DLR and Gadjah
Mada University (UGM) in 2008. Buildings were surveyed in terms of their structural stability, accessibility and holding capacity. There are two limiting factors for horizontal and vertical evacuation: time and capacity. Time has already been identified as the crucial factor in the vulnerability analysis. It sets the limit if a safe place can be reached within the available time (i.e., if the time needed for evacuation is equal to or less than the time available for evacuation). With respect to buildings suitable for evacuation, capacity acts as the second limiting factor. Buildings can only hold a certain number of evacuees. That is, even if a building is within reach to an evacuee (with respect to time), it may already be filled forcing people to head for another shelter location.

By combining the evacuation time with the detailed population distribution, the determination of those areas possible to evacuate in time and without exceeding the capacity of buildings is performed.

\subsection{Risk assessment}

The risk assessment is also GIS-based and requires the previously described parameters as inputs, namely (1) hazard probability, (2) hazard intensity (flux), (3) population density, and (4) people's response capability.

The input raster data sets are classified according to Table 2 and then overlaid.

The degree of risk is determined by a decision tree shown in Fig. 4. Unambiguously, risk class 1 indicates a very low risk and risk class 13 the highest risk. But the ranking and order of the risk classes in-between 1-13 depends on the purpose and application of the risk information and will be discussed later. 

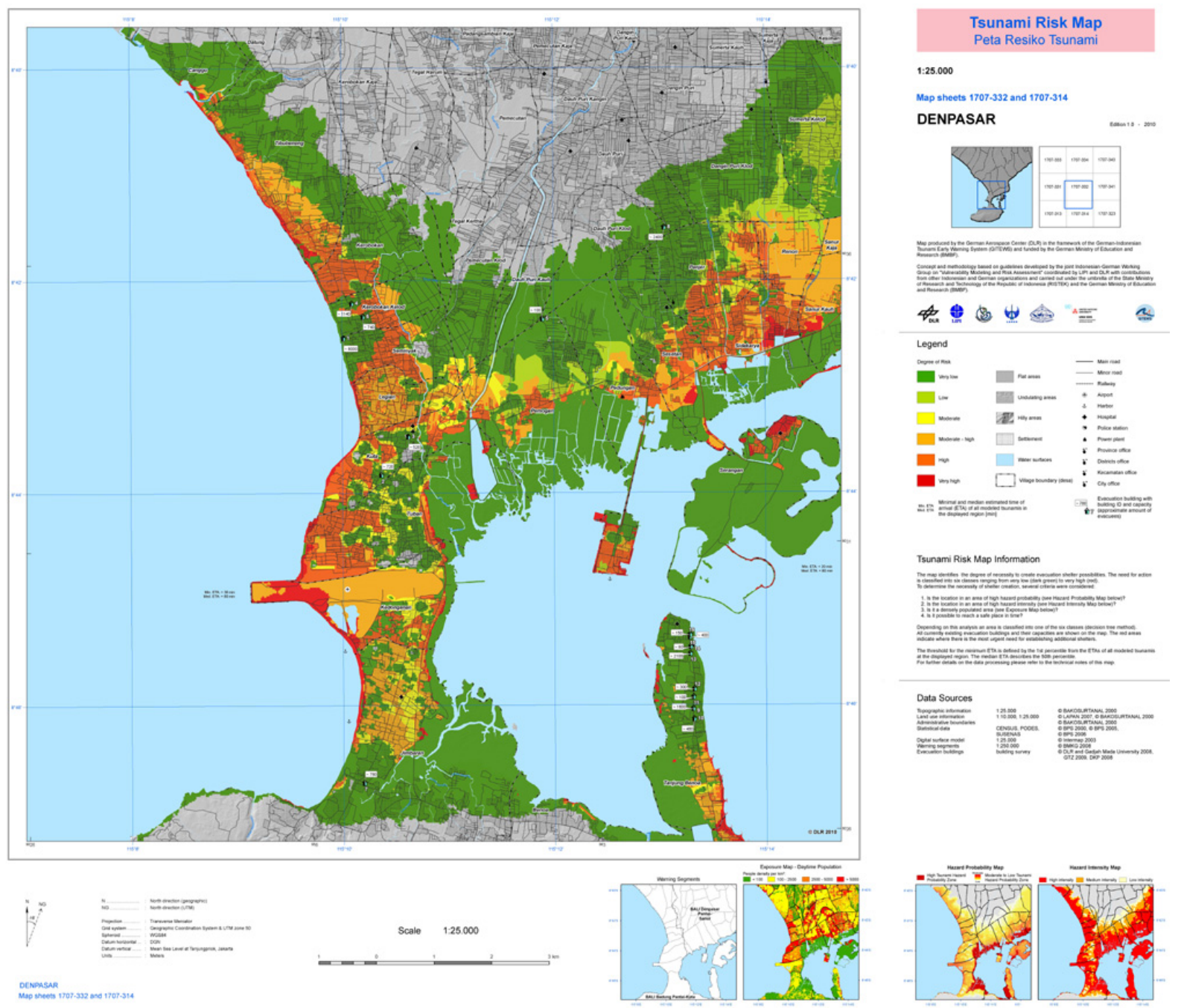

Fig. 5. Tsunami Risk Map for Bali.
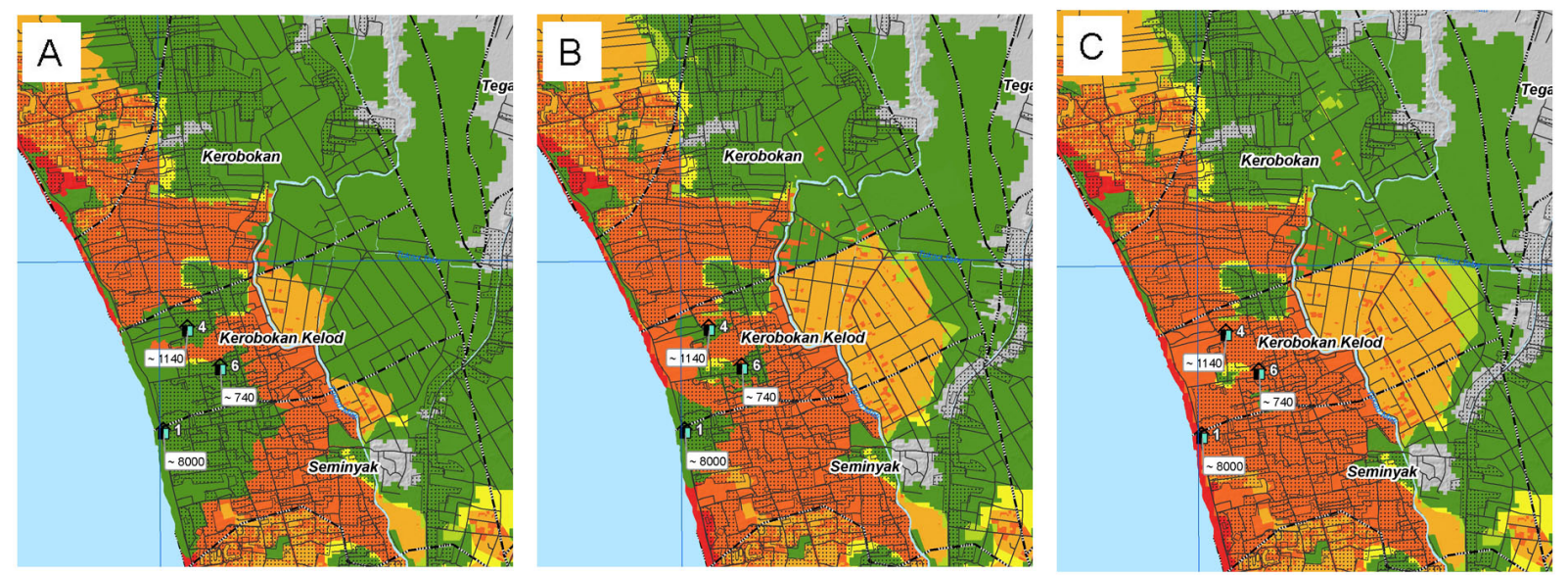

Fig. 6. Variations of risk information at different input parameters. (A) presumes an available evacuation time of 20 min and considers evacuation buildings and areas (vertical and horizontal evacuation); (B) presumes $10 \mathrm{~min}$ of available evacuation time and also considers both vertical and horizontal evacuation possibilities; (C) presumes 20 min but does not consider people's response capabilities. 


\section{Results}

In the framework of the GITEWS project, our methodology was applied to the three pilot areas, one of which is located in southern Bali and focusses on Kuta and its surroundings. Figure 5 shows the resulting risk map. It takes into account 16 potential evacuation buildings as well as horizontal evacuation possibilities.

The minimum estimated time of arrival of a tsunami is 30 min for Bali's coast in the area of Kuta. This available time frame is reduced by eight minutes which is the time needed for warning dissemination (see Fig. 3) and after reception of a warning by the population at risk by further two minutes of reaction time until evacuation measures are introduced. Consequently, in this scenario, $20 \mathrm{~min}$ are available for physical evacuation.

In order to retain the readability of the map product, the large number of risk classes as displayed in Fig. 4 were aggregated to six classes ranging from very low (dark green) to very high (red). Basically, it can be stated that the class of very low risk contains areas where either (i) people's response capability is good (i.e. a successful evacuation within $20 \mathrm{~min}$ is possible), or (ii) the modeled hazard intensity is generally low, or (iii) the population density is low (i.e. few people exposed to tsunami risk).

In contrast, high and very high risk areas are those areas where (i) additional shelter possibilities are urgently needed (moderate and high people exposure and weak response capabilities), (ii) a tsunami is likely to happen, and where (iii) the hazard intensity is high and thus buildings are likely to collapse (see Table 1). The latter one is particularly critical as buildings have to fulfil special construction criteria in order to serve as evacuation buildings and resist strong flow velocities.

\section{Discussion}

There are two different points of view on tsunami risk. On one hand, there is the planner's or the authority's perspective, which focuses on risk hotspots. A planner needs answers to questions like "Where are areas with insufficient evacuation possibilities?", "Where are additional shelters needed?" or "Where might emergency aid be most needed in case of a tsunami?". The population and also critical infrastructures have a high importance as planners need to consider the entire population at risk and organize risk reduction strategies accordingly. On the other hand, there is the perspective of an individual who focuses on their personal risk for life and property. Additionally, this individual perspective also applies to planners who focus on single infrastructures considering the question of the risk at a location where a building or road is planned. The purposes of risk products for planners as well as for individuals comprise both pre-disaster (preparedness and prevention phase) and post-disaster (emergency response and recovery phases) applications.
The risk map presented covers more the planner's interests, as a strong emphasis is placed on the population and its exposure. The map shown in Fig. 5 is a result in which the calculation of people's response capabilities considers both horizontal and vertical evacuation possibilities. Areas where evacuation is likely to be successful, i.e. an evacuation building or area can be reached within the available time, are reflected as low risk areas (dark green). Logically, these areas are subject to great variation depending on the amount of time available. Figure 6a shows an example for available evacuation time of $20 \mathrm{~min}$ while Fig. $6 \mathrm{~b}$ presumes $10 \mathrm{~min}$. Especially in the surroundings of the evacuation buildings, the reduced time makes the low risk areas significantly smaller. Thus, the areas around the three evacuation buildings are classified as high risk areas (orange) and would therefore be an area to focus planning activities on regarding additional shelters. If, however, there is enough and reliable information available about evacuation buildings and people's capabilities to reach these buildings, such areas might be excluded from shelter planning and rather become objects of activities to signpost evacuation routes and to socialize the population with evacuation procedures for that area.

Figure 6c shows an example where people's response capability was not considered but only hazard probability, hazard intensity, and population density. In comparison to Fig. 6a and b, it becomes clear that the areas farther inland, close to safe areas outside the hazard zone, are not identified as low risk areas on account of good response capabilities of the population, but rather due to the hazard components (probability and intensity). This example shows that even if it might be impossible to assess people's response capability, a reasonable assessment of the risk may be performed. Nevertheless, the assessment of people's vulnerability with respect to their evacuation abilities is an essential part of a comprehensive risk assessment and provides very valuable input for the set-up of risk reduction strategies (Post et al., 2009b).

In this study we made two crucial assumptions: first, that people do not start evacuation before they receive an institutional (technical) warning, and second, that after reception of such a warning message, they have a reaction time of two minutes before they actually start evacuating. In fact, it is also possible that people evacuate after observation of natural warning signs like ground shaking, receding shoreline or unusual sounds (Gregg et al., 2006). Such case would improve the response capability but is not taken into account here. It is therefore an important component of risk reduction strategies to socialize the population with natural tsunami warning signs. This increases the probability that people autonomously initiate evacuation measures without waiting for official warnings and orders. Similarly, this applies for the second assumption made: the assumed reaction time of two minutes is rather short and implies that people understand an issued warning, that they know how to respond to it and that they know how to reach a safe place. 
Table 3. Potential classifications of risk.

\begin{tabular}{|c|c|c|c|}
\hline \multicolumn{2}{|c|}{$\begin{array}{c}\text { Classification as in Fig. 3: Focus on } \\
\text { hazard intensity }\end{array}$} & \multicolumn{2}{|c|}{$\begin{array}{l}\text { Possible different classification: focus } \\
\text { on hazard probability }\end{array}$} \\
\hline \multirow{2}{*}{\multicolumn{2}{|c|}{$\begin{array}{l}\text { Population density: medium } \\
\text { Response capability: weak }\end{array}$}} & \multirow{2}{*}{\multicolumn{2}{|c|}{$\begin{array}{l}\text { Population density: medium } \\
\text { Response capability: weak }\end{array}$}} \\
\hline & & & \\
\hline $\begin{array}{l}\text { Hazard Probability: } \\
\text { medium }\end{array}$ & $\begin{array}{l}\text { Hazard Probability: } \\
\text { high }\end{array}$ & $\begin{array}{l}\text { Hazard Probability: } \\
\text { medium }\end{array}$ & $\begin{array}{l}\text { Hazard Probability: } \\
\text { high }\end{array}$ \\
\hline $\begin{array}{l}\text { Hazard Intensity: } \\
\text { high }\end{array}$ & $\begin{array}{l}\text { Hazard Intensity: } \\
\text { medium }\end{array}$ & $\begin{array}{l}\text { Hazard Intensity: } \\
\text { high }\end{array}$ & $\begin{array}{l}\text { Hazard Intensity: } \\
\text { medium }\end{array}$ \\
\hline$\downarrow$ & $\downarrow$ & $\downarrow$ & $\downarrow$ \\
\hline Class of higher risk & Class of lower risk & Class of lower risk & Class of higher risk \\
\hline
\end{tabular}

Gregg et al. (2006) presented in their study that, although $69 \%$ of the people had observed the receding shoreline prior to the tsunami, most of them did not evacuate. $79 \%$ of the surveyed population had to evacuate multiple times as their inital "safe" place proved unsafe (Gregg et al., 2006). These data demonstrate that socialization and education of the population including awareness raising for the risk and familiarization with natural and institutional warning signs and messages, evacuation routes and safe places should therefore be core elements of risk reduction strategies.

Figure 4 shows the risk classes in ascending order from 1 to 13 . Unambiguously, risk class 1 describes the degree of lowest risk while class 13 the highest. But the order of the classes in-between may be subject to change in some cases. There might be purposes where it is reasonable to put more weight on hazard probability than on hazard intensity. This could then mean that for example that a higher degree of risk is assigned to class 8 than to class 10 . Table 3 illustrates exemplarily the potential change of weightings of input parameters and the resulting changed risk classes.

To perform risk assessment in the way presented, it is essential to have multiple tsunami inundation and flux modeling results available. But even if no information about the flux is available, the methodology can be applied by omitting the hazard intensity and relying on hazard probability, population density and people's response capability. That way, important information for shelter planning activities is not available but still, valuable input for other disaster management activities can be provided. In some areas in Indonesia, local authorities may decide to plan on the basis of one single worst case or most probable tsunami scenario instead of a multi-scenario approach. For such areas, it would be possible to restructure the method by using, for example, inundation depths instead of hazard probabilities, or flux values only. Thus, this method is quite flexible as it is possible to adapt it according to the availability of data.

\section{Conclusions}

Few Indonesian communities in tsunami-prone areas are fully prepared for the kind of low-frequency but high-impact disasters presented by tsunamis. But at least, awareness of the risk has increased after the 2004 tsunami and fortunately, the willingness to undertake risk reduction measures as well. Thorough knowledge about tsunami risk is essential on both the part of the authorities and the population. The responsible authorities have to perform solid disaster management including warning dissemination planning, evacuation and contingency planning, and shelter planning. It is also very important to enable community members to be aware of their risk, to understand a warning, and to respond properly by having knowledge about evacuation routes and shelters and practising in advance.

In some cases, it is necessary to prioritize activities for specific areas, as limited resources do not allow local authorities to act everywhere at the same time and intensity. In order to decide about a reasonable distribution and implementation of risk reduction measures, authorities need information and knowledge about the hazard and the risk. The risk map developed in this project supports the generation of such risk knowledge, enables the identification of high risk areas, and thus allows development and implementation of risk reduction strategies based on sound risk information.

The methodology presented to produce the risk information has these great advantages: (1) flexibility with respect to needed input data and (2) practicability at a local level. By using common GIS tools available in open-source software, the risk assessment can be performed at community level without using expensive or complex software or possessing high-level expert knowledge. In order to familiarize local authorities with our method, we held several training sessions within the framework of GITEWS. These sessions included both theoretical background information as well as 
hands-on technical training. Our approach thus successfully bridges the gap between research and practical application. An update of the risk information and the application to other areas can be done by local authorities and thus enables comprehensive disaster management at community level.

Acknowledgements. This research work has been performed within the framework of the GITEWS (German Indonesian Tsunami Early Warning) project. This project is funded by the German Federal Ministry for Education and Research (BMBF), Grant 03TSU01. The authors are very grateful to all colleagues of the joint Indonesian - German working group on risk assessment and vulnerability modelling.

Edited by: S. Tinti

Reviewed by: D. Dominey-Howes and C. E. Gregg

\section{References}

Babeyko, A. Y., Hoechner, A., and Sobolev, S. V.: Source modeling and inversion with near real-time GPS: a GITEWS perspective for Indonesia, Nat. Hazards Earth Syst. Sci., 10, 1617-1627, doi:10.5194/nhess-10-1617-2010, 2010.

Bird, D. and Dominey-Howes, D.: Testing the use of a 'questionnaire survey instrument' to investigate public perceptions of tsunami hazard and risk in Sydney, Australia. Natural Hazards, 45, 99-122, 2008.

Clieh, M., Avouac, J. P., Sieh, K., Natawidjaja, D. H., and Galetzka, J.: Heterogeneous coupling of the Sumatran megathrust constrained by geodetic and paleogeodetic measurements, J. Geophys. Res., 113, 1-31, 2008.

Coastal Development Institute of Technology (CDIT) (Ed.): Menyelamatkan diri dari tsunami, Penerbit Buku Ilmiah Populer Press, Bogor, Indonesia, 2009.

Dall'Osso, F. and Dominey-Howes, D.: Public assessment of the usefulness of "draft" tsunami evacuation maps from Sydney, Australia - implications for the establishment of formal evacuation plans, Nat. Hazards Earth Syst. Sci., 10, 1739-1750, doi:10.5194/nhess-10-1739-2010, 2010.

Gayer, G., Nöhren, I., Leschka, S., and Kongko, W.: Detailed investigation of tsunami scenarios in coastal areas and onshore, International Conference on Tsunami Warning (ICTW), Bali, Indonesia, 12-14 November 2008.

Gregg, C. E., Houghton, B. F., Paton, D., Lachmann, R., Lachmann, J., Johnston, D. M., and Wongbusarakum, S.: Natural warning signs of tsunamis: human sensory experience and response to the 2004 great Sumatra earthquake and tsunami in Thailand, Earthq. Spectra, 22, S3, 671-691, 2006.

Jonkman, S. N. and Vrijling, J. K.: Loss of life due to floods, Journal of Flood Risk Management, 1, 43-56, 2008.

Khomarudin, M. R., Strunz, G., Post, J., Zosseder, K., and Ludwig, R.: Spatial improvement of information on population distribution using GIS approaches: an input for tsunami people exposure assessment, Int. J. Earth Sci. Remote Sens., 6, 46-56, 2009.

Khomarudin, M. R., Strunz, G., Ludwig, R., Zosseder, K., Post, J., Kongko, W., and Pranowo, W. S.: Hazard analysis and estimation of people exposure as contribution to tsunami risk assessment in the west coast of Sumatra, the south coast of Java and Bali, Z. Geomorphol., 54, Suppl. 3, 337-356, 2010.
Latief, H., Puspito, N. T., and Imamura, F.: Tsunami catalogue and zones in Indonesia, Journal of Natural Disaster Science, 22/1, 25-43, 2000.

McCloskey, J., Antonioli, A., Piatanesi, A., Sieh, K., Steacy, S., Nalbant, S., Cocco, M., Giunchi, C., Huang, J. D., and Dunlop, P.: Tsunami threat in the Indian Ocean from a future megathrust earthquake west of Sumatra, Earth Planet. Sc. Lett., 265, 61-81, 2008.

Papathoma, M.: Tsunami vulnerability assessment using a geographical information system with special reference to Greece. Ph.D. thesis, Coventry University, Coventry, UK, 292, 2003.

Post, J., Zoßeder, K., and Strunz, G.: Framework and indicators for vulnerability assessment: vulnerability mapping to tsunami disaster in the context of early warning in Indonesia. Integrating Socio-economic and Remote Sensing Information (Ispra), Italy, 19 September 2007, 2007a.

Post, J., Zoßeder, K., Strunz, G., Birkmann, J., Gebert, N., Setiadi, N., Anwar, H.Z., Harjono, H., Nur, M., and Siagian, T.: Risk and vulnerability assessment to tsunami and coastal hazards in Indonesia: conceptual framework and indicator development. International Symposium on Disaster in Indonesia, Padang, Indonesia, 2007b.

Post, J., Mück, M., Zoßeder, K., Wegscheider, S., Taubenböck, H., Strunz, G., Muhari, A., Anwar, H. Z., Birkmann, J., and Gebert, N.: Quantifying human response capabilities towards tsunami threats at community level, EGU General Assembly, Vienna, Austria, 19-24 April 2009, EGU2009-12665, 2009a.

Post, J., Wegscheider, S., Mück, M., Zosseder, K., Kiefl, R., Steinmetz, T., and Strunz, G.: Assessment of human immediate response capability related to tsunami threats in Indonesia at a sub-national scale, Nat. Hazards Earth Syst. Sci., 9, 1075-1086, doi:10.5194/nhess-9-1075-2009, 2009b.

Post, J., Zoßeder, K., Wegscheider, S., Steinmetz, T., Mück, M., Strunz, G., Riedlinger, T., Anwar, H. Z., Birkmann, J., and Gebert, N.: Tsunami prevention and mitigation necessities and options derived from tsunami risk assessment in Indonesia, EGU General Assembly, Vienna, Austria, 19-24 April 2009, EGU2009-12632, 2009c.

RESCDAM: The use of physical models in dam-break flood analysis, Final report of Helsinki University of Technology, available at: http://www.ymparisto.fi/download.asp?contentid= 13494\\&lan=fi (access: 17 June 2010) 2000.

Rudloff, A., Lauterjung, J., Münch, U., and Tinti, S.: Preface "The GITEWS Project (German-Indonesian Tsunami Early Warning System)", Nat. Hazards Earth Syst. Sci., 9, 1381-1382, doi:10.5194/nhess-9-1381-2009, 2009.

Rynn, J. and Davidson, J.: Contemporary assessment of tsunami risk and implications for early warnings for Australia and its island territories, Science of Tsunami Hazards, 17, 107-125, 1999.

Spahn, H., Hoppe, M., Vidiarina, H. D., and Usdianto, B.: Experience from three years of local capacity development for tsunami early warning in Indonesia: challenges, lessons and the way ahead, Nat. Hazards Earth Syst. Sci., 10, 1411-1429, doi:10.5194/nhess-10-1411-2010, 2010.

Strunz, G., Post, J., Zosseder, K., Wegscheider, S., Mück, M., Riedlinger, T., Mehl, H., Dech, S., Birkmann, J., Gebert, N., Harjono, H., Anwar, H. Z., Sumaryono, Khomarudin, R. M., and Muhari, A.: Tsunami risk assessment in Indonesia, Nat. Hazards Earth Syst. Sci., 11, 67-82, doi:10.5194/nhess-11-67-2011, 
2011.

Taubenböck, H., Goseberg, N., Setiadi, N., Lämmel, G., Moder, F., Oczipka, M., Klüpfel, H., Wahl, R., Schlurmann, T., Strunz, G., Birkmann, J., Nagel, K., Siegert, F., Lehmann, F., Dech, S., Gress, A., and Klein, R.: "Last-Mile" preparation for a potential disaster - Interdisciplinary approach towards tsunami early warning and an evacuation information system for the coastal city of Padang, Indonesia, Nat. Hazards Earth Syst. Sci., 9, 1509-1528, doi:10.5194/nhess-9-1509-2009, 2009.

UNESCO IOC (ed.): Hazard awareness and risk mitigation in integrated coastal management (ICAM). Intergovernmental Oceanographic Commission, IOC Manual and Guides No. 50, ICAM Dossier No. 5, Paris, UNESCO, 2009.
United Nations/ISDR (International Strategy for Disaster Reduction): Living with risk: A global review of disaster reduction initiatives, United Nations International Strategy for disaster Reduction, UN Publications, Geneva, Switzerland, 2004.

Zoßeder, K., Post, J., Steinmetz, T., Wegscheider, S., and Strunz, G.: Using multi-scenario tsunami modelling results combined with probabilistic analyses to provide hazard information for the south-west coast of Indonesia, EGU General Assembly, Vienna, Austria, 19-24 April 2009, EGU2009-12635, 2009. 